\title{
Prevalence of nephropathy and proximal tubule disorder in human immunodeficiency virus patients under tenofovir therapy
}

\author{
Foroogh Sabzghabaei $^{\circledR}$, Afsaneh Sedighi $^{2^{*}}{ }^{\circledR}$, Raziyeh Shahi $^{2^{\circledR}}$, Vahid Mahmoodi $^{{ }^{\circledR}}$, Jahanbakhsh \\ Khamseh $^{2 \mathbb{D}}$, Neda Rahimian ${ }^{2}$ \\ ${ }^{1}$ Department of Medicine, Firoozabadi Hospital, Iran University of Medical Sciences, Tehran, Iran \\ ${ }^{2}$ Department of Internal Medicine, Firoozgar Clinical Research Development Center (FCRDC), Iran University of Medical Sciences, \\ Tehran, Iran
}

\section{A R T I C L E I N F O}

Article Type:

Original

\section{Article History:}

Received: 24 May 2021

Accepted: 2 September 2021

ePublished: 12 September 2021

\section{Keywords:}

Human immunodeficiency virus Tenofovir

Nephropathy

\begin{abstract}
A B S T R A C T
Introduction: Tenofovir is a common therapy in human immunodeficiency virus (HIV) patients.

Objective: This study was carried out to determine the prevalence of nephropathy and proximal tubule disorder in HIV patients under tenofovir therapy.

Patients and Methods: In this study, $160 \mathrm{HIV}$ patients under tenofovir therapy were enrolled and the prevalence of nephropathy and proximal tubule disorder was determined and compared.

Results: We found, the proximal tubule involvement in $25 \%, 6.8 \%, 2.2 \%$ and $0 \%$ in first year, 2-5 years , 6-10 years and 11-18 years of disease involvement respectively, $(P=0.02)$. The mean glomerular filtration rate (GFR) diminution was $2.15 \%, 10.53 \%, 12.6 \%$ and $17.79 \%$, in the first, $2-5,6-10$, and 11-18 years, respectively, again showing a significant difference between years $(P=0.02)$. Proteinuria was seen in $13.1 \%$ of patients.

Conclusion: We concluded that GFR diminution and proximal tubule involvement are common and important to be managed in HIV-positive patients under tenofovir therapy, and discontinuation of drug has no positive effect on GFR.
\end{abstract}

Implication for health policy/practice/research/medical education:

This study reflects complications related to administration of tenofovir in human immunodeficiency virus (HIV) patients and could serve as a practical guide for HIV specialists in administration of HIV antiviral therapy.

Please cite this paper as: Sabzghabaei F, Sedighi A, Shahi R, Mahmoodi V, Khamseh J, Rahimian N. Prevalence of nephropathy and proximal tubule disorder in human immunodeficiency virus patients under tenofovir therapy. J Nephropharmacol. 2022;11(1):e11. DOI: 10.34172/npj.2022.11.

\section{Introduction}

Human immunodeficiency virus (HIV) is one of the most common fatal infectious diseases found worldwide and the highly active antiretroviral therapy (HAART) is the most recommended therapeutic option for these patients (1). However, no single therapy is approved for HIV patients $(1,2)$. Tenofovir is a nocloside transcriptase inhibitor acting via interaction with function of RNArelated DNA polymerase, leading to viral inhibition and it is a first-line HIV treatment in many countries in patients with urinary excretion $(1,2)$.

Tenofovir is contraindicated in renal failure patients (35). It can result in proximal tubule involvement similar to Fanconi syndrome with a normal anion gap and with hypophosphatemia, hyperphosphaturia, hypokalemia, hypouricemia, tubular proteinuria, glycosuria, aminoaciduria, and osteomalacia (4-7). On renal biopsy, acute extensive tubular necrosis in proximal kidney tubuls is found (8-10). Some of the alterations are reversible $(3,11,12)$.

\section{Objectives}

Tenofovir is a common therapy in HIV patients, and nephropathy is its main therapeutic adverse effect. Hence, considering the necessity for the preservation of renal function in these patients amidst scarcity of studies on Iranians, this study was conducted to determine prevalence of nephropathy and proximal tubule disorder 
in HIV patients under tenofovir therapy in Iran.

\section{Patients and Methods}

Study design

In this cohort, 160 consecutive HIV patients under tenofovir therapy from September 2018 to April 2020 were enrolled. The exclusion criteria were chronic kidney disease stage 4 and end-stage renal disease. Data were collected through a checklist. The variables included age, gender, age of onset, duration of treatment, background diseases, smoking, alcohol use, drug/opium use, vital signs, glomerular filtration rate (GFR), creatinine, urea, uric acid (UA), sodium, and potassium. The UA, creatinine, and urea were checked every three months. In cases with increase in creatinine, the tenofovir was discontinued, and the effect on GFR level was assessed. The prevalence of nephropathy and proximal tubule disorder was determined in patients and was compared by other variables.

\section{Data analysis}

Data analysis was carried out by the SPSS version 25.0 software. The different types of tests employed included ANOVA, Chi-squared, independent sample $t$ test, and post-hoc Tukey's assays. $P$ values under 0.05 were considered as statistically significant.

\section{Results}

In this study, 101 (63.1\%) patients were male and the mean (standard deviation) age was 43.3 years (11.2 years) (range; 9-72 years). In total, 82 cases (51.3\%) were married. The mean (standard deviation) body mass index (BMI) was $24.9 \mathrm{~kg} / \mathrm{m}^{2}\left(4.5 \mathrm{~kg} / \mathrm{m}^{2}\right)$. Around 31 cases (19.4\%) had academic literacy. Duration of HIV in "less than five years", "between 5 and 10 years" and "more than 10 years" were in $42.5 \%, 29.3 \%$ and $18.2 \%$ of subjects respectively. However, the average duration was 6.6 years ( 4.3 years). As shown in Table 1, the main transmission route was sexual relationship (45\%). Continuous non-steroidal anti-inflammatory drug (NSAID) use over the last year was reported in $60.6 \%$ of cases and $30 \%$ of cases were smokers too. In addition, $1.9 \%$ of patients were also using intravenous opioids. The history of background diseases is shown in Table 2. The mean serum creatinine was 0.96 $\mathrm{mg} / \mathrm{dL}, 0.98 \mathrm{mg} / \mathrm{dL}$ and $1.09 \mathrm{mg} / \mathrm{dL}$ in baseline, after six months and at the final stage, respectively. GFR decrease was one of the causes of tenofovir discontinuation in $55 \%$ of cases. The other causes are shown in Table 3. The laboratory results are shown in Table 4.

The first and second therapeutic regimens in patients are shown in Table 5. The mean GFR initially was 89.98 (17.78) and the finally 77.95 (18.62), showing a significant difference $(P=0.001)$. The GFR level lower than $90 \mathrm{mg} / \mathrm{dL}$ was increased by $74.4 \%$.

There was GFR decrease in $84.4 \%$ of cases compared
Table 1. Route of HIV transmission in patients

\begin{tabular}{lll}
\hline Route & No. & $\%$ \\
\hline Partner & 38 & 23.8 \\
Sexual relationship & 72 & 45.0 \\
Blood & 48 & 30.0 \\
Maternal & 2 & 1.3 \\
Total & 160 & 100.0 \\
\hline
\end{tabular}

Table 2. Disease background of patients

\begin{tabular}{lll}
\hline Disease & No. & \% \\
\hline DM & 4 & 2.5 \\
Tuberculosis & 18 & 11.3 \\
HTN & 6 & 3.8 \\
CKD & 11 & 6.9 \\
HBV & 4 & 2.5 \\
HCV & 30 & 18.8 \\
\hline
\end{tabular}

Table 3. Causes for tenofovir discontinuation in patients

\begin{tabular}{lll}
\hline Cause & No. & $\%$ \\
\hline Osteopenia & 9 & 45.0 \\
Lack of response & 6 & 30.0 \\
GFR decrease and osteopenia & 5 & 25.0 \\
Total & 20 & 100.0 \\
\hline
\end{tabular}

Table 4. Laboratory results of patients

\begin{tabular}{lcccc}
\hline Test & Mean & SD & Minimum & Maximum \\
\hline AST (unit/L) & 26.25 & 14.54 & 5 & 116 \\
ALT (unit/L) & 32.34 & 19.91 & 7 & 132 \\
LDL-c (mg/dL) & 100.41 & 32.01 & 27 & 219 \\
HDL-c (mg/dL) & 45.03 & 12.79 & 20 & 97 \\
TG (mg/dL) & 154.23 & 90.99 & 42 & 562 \\
WBC-FIRST (per $\mu \mathrm{L})$ & 5651.04 & 1951.74 & 5 & 12540 \\
WBC-LAST (per $\mu \mathrm{L})$ & 6049.98 & 2343.52 & 6 & 19800 \\
CD4-FIRST (per $\mu \mathrm{L})$ & 389.28 & 334.08 & 1 & 3028 \\
\hline
\end{tabular}

with measurements conducted before the treatment. In total, $13.1 \%$ of the patients had proteinuria, including $1+$, $2+$ and $3+$ in $8.8 \%, 2.5 \%$ and $1.9 \%$ of cases, respectively. The GFR alteration rates are shown in Table 6. Only inhalational opium use $(P=0.001)$, as shown in Table 7 , was related to GFR alterations in patients. The mean CD4 count was initially 389.28 (334.08), and the final mean GFR level was 620.94 (284.24), showing a significant difference $(P=0.001)$. CD4 count was increased by $83.1 \%$, with a mean increase of 319.4 (188.6) and mean decrease of 235.24 (422.29). There was a significant correlation between CD4 count and GFR level $(P=0.001)$.

In this study, the proximal tubule involvement was $25 \%, 6.8 \%, 2.2 \%$, and $0 \%$ in the first year, at $2-5$ years, at 6-10 years and at 11-18 years, respectively, showing a 
Table 5. Utilized therapeutic regimens in the patients

\begin{tabular}{|c|c|c|}
\hline & No. & $\%$ \\
\hline \multicolumn{3}{|l|}{ Initial regimen } \\
\hline $\mathrm{TDF}+\mathrm{FTC}+\mathrm{ATV} / \mathrm{r}$ & 16 & 10.0 \\
\hline $\mathrm{TDF}+\mathrm{FTC}+\mathrm{LPV} / \mathrm{r}$ & 2 & 1.3 \\
\hline $\mathrm{TDF}+\mathrm{FTC}+\mathrm{EFV}$ & 104 & 65.0 \\
\hline $\mathrm{TDF}+\mathrm{FTC}+\mathrm{RAL}$ & 3 & 1.9 \\
\hline$T D F+F T C+R A L+A T V / r$ & 3 & 1.9 \\
\hline $\mathrm{TDF}+\mathrm{FTC}+\mathrm{DTG}$ & 4 & 2.5 \\
\hline $\mathrm{DTG}+3 \mathrm{TC}+\mathrm{TAF}$ & 1 & 0.6 \\
\hline $\mathrm{EFV}+3 \mathrm{TC}+\mathrm{TAF}$ & 2 & 1.3 \\
\hline $\mathrm{FTC}+\mathrm{TAF}+\mathrm{ATV} / \mathrm{r}$ & 1 & 0.6 \\
\hline$T D F+3 T C+A T V / r$ & 6 & 3.8 \\
\hline$T D F+E F V+3 T C$ & 12 & 7.5 \\
\hline $3 T C+T D F+L P V / r$ & 2 & 1.3 \\
\hline$T D F+A T V / r+3 T C$ & 1 & 0.6 \\
\hline$A Z T+E F V+3 T C$ & 1 & 0.6 \\
\hline$A B C+T D F+L P V / r$ & 1 & 0.6 \\
\hline $\mathrm{NV}+\mathrm{TDF}+\mathrm{FTC}$ & 1 & 0.6 \\
\hline \multicolumn{3}{|l|}{ Second regimen } \\
\hline $3 T C+E F V+A B C$ & 6 & 3.8 \\
\hline$A T V / r+3 T C+A B C$ & 2 & 1.3 \\
\hline $3 T C+T A F+E F V$ & 1 & 0.6 \\
\hline$A Z T+3 T C+A T V / r$ & 3 & 1.9 \\
\hline $3 T C+A T V / r+D T G$ & 1 & 0.6 \\
\hline $3 T C+A Z T+D T G$ & 1 & 0.6 \\
\hline $\mathrm{FTC}+\mathrm{TAF}+\mathrm{EFV}$ & 3 & 1.9 \\
\hline $3 T C+A Z T+E F V$ & 2 & 1.3 \\
\hline $\mathrm{FTC}+3 \mathrm{TC}+\mathrm{DTG}$ & 1 & 0.6 \\
\hline$T D F+3 T C+A T V / r$ & 1 & 0.6 \\
\hline $\mathrm{TDF}+\mathrm{FTC}+\mathrm{EFV}$ & 2 & 1.3 \\
\hline $\mathrm{EFV}+3 \mathrm{TC}+\mathrm{TAF}$ & 3 & 1.9 \\
\hline$A B C+D T G+R T V+3 T C$ & 1 & 0.6 \\
\hline
\end{tabular}

TDF, tenofovir disoproxil fumarate; FTC, emtricitabine; ATV/r, atazanavir/ ritonavir; LPV/r, lopinavir/ritonavir; EFV, efavirenz; RAL, raltegravir; DTG, dolutegravir; 3TC, lamivudine; TAF, tenofovir alafenamide; AZT, Zidovudine; $A B C$, abacavir; NVP, nevirapine; RTV, ritonavir.

Table 6. GFR alteration rates in patients $\left(\mathrm{mL} / \mathrm{min} / 1 / 73 \mathrm{~m}^{2}\right)$

\begin{tabular}{lcccc}
\hline GFR & Mean & SD & Minimum & Maximum \\
\hline Mean increase & 12.04 & 12.74 & 0.0 & 51.00 \\
Mean decrease & -16.48 & 12.68 & -50.00 & -1.00 \\
\hline
\end{tabular}

significant difference $(P=0.02)$. The mean GFR decrease was $2.15 \%, 10.53 \%, 12.6 \%$ and $17.79 \%$, in the first year, at $2-5$ years, at $6-10$ years, and at $11-18$ years, respectively, showing a significant difference $(P=0.02)$. Tenofovir discontinuation was not related to last GFR level $(P=0.4)$.

\section{Discussion}

In this study, the rate and extent of nephropathy due to tenofovir use was determined in HIV-positive cases. Proximal tubule disorders were seen in $25 \%, 6.8 \%$ and $2.2 \%$ in the first year, at 2-5 years, and at 6-10 years of tenofovir use; however, thereafter no cases were seen until 18 years later. It was related to duration of use. The mean rate of GFR
Table 7. GFR measurements based on other variables

\begin{tabular}{|c|c|c|c|}
\hline NSAID & Mean first GFR & SD & $P$ value \\
\hline No & 88.25 & 16.87 & \multirow{2}{*}{0.3} \\
\hline Yes & 91.09 & 18.48 & \\
\hline NSAID & Mean last GFR & SD & \\
\hline No & 76.81 & 17.31 & \multirow{2}{*}{0.5} \\
\hline Yes & 78.69 & 19.47 & \\
\hline Smoking & Mean first GFR & SD & \\
\hline Yes & 94.43 & 15.18 & \multirow{2}{*}{0.07} \\
\hline No & 88.57 & 18.63 & \\
\hline Smoking & Mean last GFR & SD & \\
\hline Yes & 79.19 & 15.50 & \multirow{2}{*}{0.5} \\
\hline No & 77.46 & 19.85 & \\
\hline Opium use & Mean first GFR & SD & \\
\hline Yes & 89.67 & 21.93 & \multirow{2}{*}{0.9} \\
\hline No & 89.98 & 17.87 & \\
\hline Opium use & Mean last GFR & SD & \\
\hline Yes & 67.11 & 15.68 & \multirow{2}{*}{0.001} \\
\hline No & 80.25 & 18.43 & \\
\hline Diabetes & Mean first GFR & SD & \\
\hline Yes & 86.75 & 12.42 & \multirow{2}{*}{0.6} \\
\hline No & 90.06 & 18.0 & \\
\hline Diabetes & Mean last GFR & SD & \\
\hline Yes & 82.75 & 33.45 & \multirow{2}{*}{0.6} \\
\hline No & 77.83 & 18.25 & \\
\hline TB history & Mean first GFR & SD & \\
\hline Yes & 91.72 & 20.76 & \multirow{2}{*}{0.6} \\
\hline No & 89.75 & 17.54 & \\
\hline TB history & Mean last GFR & SD & \\
\hline Yes & 77.67 & 16.47 & \multirow{2}{*}{0.9} \\
\hline No & 77.99 & 18.92 & \\
\hline Hypertension & Mean first GFR & SD & \\
\hline Yes & 92.17 & 23.86 & \multirow{2}{*}{0.9} \\
\hline No & 89.89 & 17.69 & \\
\hline Hypertension & Mean last GFR & SD & \\
\hline Yes & 68.17 & 11.97 & \multirow{2}{*}{0.7} \\
\hline No & 78.33 & 18.75 & \\
\hline
\end{tabular}

fall was $2.15 \%, 10.53 \%, 12.6 \%$ and $17.79 \%$ in the first year, at 2-5 years, at 6-10 years and at 11-18 years, respectively, showing a significant difference. For this reason, this effective and potent drug may be administered in the first treatment year and then can be replaced with other drugs for safety. The GFR improvement was not attained with tenofovir discontinuation, showing the irreversibility of the nephropathy in patients. Of 160 patients, 21 cases had overt proteinuria (3+), which underwent kidney biopsy. In one case, there was tubulointerstitial lesions due to HIVassociated nephropathy. In addition, there was one case of focal segmental glomerulosclerosis (FSGS) and the other with diabetic nephropathy. This is in line with the study conducted by previous authors; however, with a smaller sample size. This study showed that kidney involvement in HIV patients has shifted from HIVAN to immunecomplex GN and diabetic nephropathy and FSGS cases.

The study by De Waal et al on 15156 cases showed, patients with lower initial GFR had a higher rate of renal 
adverse effects (13). Moreover, Weaver et al, reported that of $24 \mathrm{HIV}$-positive cases under tenofovir therapy, $42 \%$ had reversible outcomes (3). However, in our study with a larger same size, the irreversible cases were more common. In another study on 213 Brazilian patients, the cardiovascular disease rate was higher in cases undergoing tenofovir therapy (4). However, in our study, no comparison was conducted with other drugs due to some limitations.

In the study by Waheed et al, on 15 cases under tenofovir therapy, of total patients, 11 patients had GFR more than 90 and the duration of treatment was considered 64 months (5). The mean GFR was decreased from 104 $\mathrm{mL} / \mathrm{min}$ to $69 \mathrm{~mL} / \mathrm{min}$ and then it was improved but not completely after drug discontinuation. This similarly shows the irreversible pattern. Herlitz et al, reported a rate of $61 \%$ for acute kidney injury and $15 \%$ for anuria (6). The difference in results of their survey may be due to a smaller sample size compared with our study.

A cross-sectional study on 101 patients showed that creatinine rise, proteinuria and tubular dysfunction were present in $7 \%, 37 \%$ and $15 \%$ of cases, respectively (7). However, these rates were lower in our study due to a shorter follow-up length. Gerard et al, assessed 53 patients under tenofovir therapy for 13 months (8). They found, GFR was decreased at a rate of $7.8 \mathrm{~mL} / \mathrm{min}$ versus the control group. However, we had no control group for comparison and such design may be pursued in future studies. Crane et al reported a mean GFR decrease rate of $7 \mathrm{~mL} / \mathrm{min}$, leading to a rate of less than $60 \mathrm{ml} / \mathrm{min}$ in $2 \%$ of cases, similar to our study (9).

A review study by Jafari et al showed that older age, opium or NSAIDs use, low weight, low CD4+ count and high-dose and long-term tenofovir therapy were related to renal disorders in HIV cases under tenofovir therapy (14). Among these factors, only low CD4 cell count was related to nephropathy. Liu et al assessed 823 adult cases with GFR over $90 \mathrm{ml} / \mathrm{min}$. They found, $21.6 \%$ had renal failure with an S-shaped pattern of renal function (15). The difference was especially higher between the first and fourth year of tenofovir therapy. Hence, tenofovir may be administered in the first year of treatment and then replaced with other agents.

Hoang et al reported that $8.5 \%$ out of 400 cases under tenofovir therapy had renal dysfunction that was related to older age, lower BMI and no exposure to isoniazid therapy (16). Anthropometric and demographic variables and tuberculosis treatment in our study were not related to renal function. Accordingly, Gupta et al, showed the importance of the type of salt used in tenofovir. This may be a possible cause of differences between results of various studies (17).

\section{Conclusion}

In this study, we concluded that GFR diminution and proximal tubule involvement are common and important to be managed in HIV-positive patients under tenofovir therapy, since discontinuation of the drug has no positive effect on GFR. Regarding the results, treatment with tenofovir in the initial two years is rational and then replacement with other drugs may be considered. However, further studies with a larger sample size and multi-center sampling can lead to more definitive results.

Limitations of the study

Main limitations of our study are a smaller sample size and a shorter patient follow-up period. Further studies with a larger sample size and long-term-follow up are recommended.

\section{Authors' contribution}

AS, FS and KE were the principal investigators of the study. RS, JKh, VM and NR were involved in preparing the concept and design of this study. VM and JKh revisited the manuscript and critically evaluated the intellectual contents. All authors participated in preparing the final draft of the manuscript, revising the manuscript and critically evaluating the intellectual contents. All authors have read and approved the content of the manuscript and confirmed the accuracy or integrity of any part of the work.

\section{Conflicts of interest}

The authors declare that they have no competing interests.

\section{Ethical issues}

The research followed the tenets of the Declaration of Helsinki. The Ethics Committee of the Iran University of Medical Sciences approved this study. The institutional ethics committee of the Iran University of Medical Sciences approved all study protocols (IR.IUMS.FMD. REC1396.9511160009). Accordingly, written informed consent was obtained from all participants before any intervention. This study was part of the M.D. thesis of Mahmoodi being pursued at this university (Thesis\#2952). Besides, ethical issues (including plagiarism, data fabrication and repeat publication) have been completely addressed by the authors.

\section{Funding/Support}

This study was supported by the Clinical Research Development Center (FCRDC), Iran University of Medical Sciences, Tehran, Iran.

\section{Reference}

1. Kasper D, Fauci A, Hauser S, Longo D, Jameson J, Loscalzo J. Harrison's Principles of Internal Medicine. 19th ed. New York, NY: McGraw Hill; 2015.

2. Kearney BP, Flaherty JF, Shah J. Tenofovir disoproxil fumarate: clinical pharmacology and pharmacokinetics. Clin 
Pharmacokinet. 2004;43:595-612. doi: 10.2165/00003088200443090-00003.

3. Wever K, van Agtmael MA, Carr A. Incomplete reversibility of tenofovir-related renal toxicity in HIV-infected men. J Acquir Immune Defic Syndr. 2010;55:78-81. doi: 10.1097/ QAI.0b013e3181d05579.

4. Menezes AM, Torelly J, Jr., Real L, Bay M, Poeta J, Sprinz E. Prevalence and risk factors associated to chronic kidney disease in HIV-infected patients on HAART and undetectable viral load in Brazil. PLoS One. 2011;6:e26042. doi: 10.1371/journal.pone.0026042.

5. Waheed S, Attia D, Estrella MM, Zafar Y, Atta MG, Lucas GM, et al. Proximal tubular dysfunction and kidney injury associated with tenofovir in HIV patients: a case series. Clin Kidney J. 2015;8:420-5. doi: 10.1093/ckj/sfv041.

6. Herlitz LC, Mohan S, Stokes MB, Radhakrishnan J, D’Agati VD, Markowitz GS. Tenofovir nephrotoxicity: acute tubular necrosis with distinctive clinical, pathological, and mitochondrial abnormalities. Kidney Int. 2010;78:1171-7. doi: $10.1038 / \mathrm{ki} .2010 .318$.

7. Chadwick DR, Sarfo FS, Kirk ES, Owusu D, Bedu-Addo G, Parris V, et al. Tenofovir is associated with increased tubular proteinuria and asymptomatic renal tubular dysfunction in Ghana. BMC Nephrol. 2015;16:195. doi: 10.1186/s12882015-0192-4.

8. Gérard L, Chazallon C, Taburet AM, Girard PM, Aboulker JP, Piketty C. Renal function in antiretroviralexperienced patients treated with tenofovir disoproxil fumarate associated with atazanavir/ritonavir. Antivir Ther. 2007;12:31-9.

9. Crane HM, Kestenbaum B, Harrington RD, Kitahata MM. Amprenavir and didanosine are associated with declining kidney function among patients receiving tenofovir. AIDS. 2007;21:1431-9. doi: 10.1097/QAD.0b013e3281fc9320.

10. Woodward CL, Hall AM, Williams IG, Madge S, Copas A, Nair D, et al. Tenofovir-associated renal and bone toxicity. HIV Med. 2009;10:482-7. doi: 10.1111/j.14681293.2009.00716.x.

11. Rho M, Perazella MA. Nephrotoxicity associated with antiretroviral therapy in HIV-infected patients. Curr Drug Saf. 2007;2:147-54. doi: 10.2174/157488607780598269.

12. Fine DM, Perazella MA, Lucas GM, Atta MG. Renal disease in patients with HIV infection: epidemiology, pathogenesis and management. Drugs. 2008;68:963-80. doi: $\quad 10.2165 / 00003495-200868070-00006$.

13. De Waal R, Cohen K, Fox MP, Stinson K, Maartens G, Boulle A, et al. Changes in estimated glomerular filtration rate over time in South African HIV-1-infected patients receiving tenofovir: a retrospective cohort study. J Int AIDS Soc. 2017;20:21317. doi: 10.7448/ias.20.01/21317.

14. Jafari A, Khalili H, Dashti-Khavidaki S. Tenofovir-induced nephrotoxicity: incidence, mechanism, risk factors, prognosis and proposed agents for prevention. Eur J Clin Pharmacol. 2014;70:1029-40. doi: 10.1007/s00228-0141712-z.

15. Liu F, Xu A, Zhao H, Yang Z, Chen C, Ranieri B, et al. Longitudinal progression of estimated GFR in HIV-1infected patients with normal renal function on tenofovirbased therapy in China. Ther Clin Risk Manag. 2020;16:299310. doi: $10.2147 /$ tcrm.s243913.

16. Hoang CQ, Nguyen HD, Vu HQ, Nguyen KT, Hoang LT, Ly $\mathrm{H}$, et al. Determinants of risk factors for renal impairment among HIV-infected patients treated with tenofovir disoproxil fumarate-based antiretroviral regimen in Southern Vietnam. Biomed Res Int. 2020;2020:7650104. doi: 10.1155/2020/7650104.

17. Gupta SK, Post FA, Arribas JR, Eron JJ Jr, Wohl DA, Clarke AE, et al. Renal safety of tenofovir alafenamide vs. tenofovir disoproxil fumarate: a pooled analysis of 26 clinical trials. AIDS. 2019;33:1455-65. doi: 10.1097/ qad.0000000000002223.

Copyright $\odot 2022$ The Author(s); Published by Society of Diabetic Nephropathy Prevention. This is an open-access article distributed under the terms of the Creative Commons Attribution License (http://creativecommons.org/licenses/by/4.0), which permits unrestricted use, distribution, and reproduction in any medium, provided the original work is properly cited. 